\title{
Mainstreaming Adaptation to Climate Change in Coastal Bangladesh by building Civil Society Alliances
}

\author{
Frank Thomalla ${ }^{1}$, Terry Cannon ${ }^{2}$, Saleemul $\mathrm{Huq}_{5}^{3}$, Richard J. T. Klein ${ }^{4}$, and Claudia \\ Schaerer $^{5}$
}

\begin{abstract}
Bangladesh is one of the world's poorest countrie s and is prone to a multitude of climate-related impacts such as floods, droughts, tropical cyclones and storm surges. The vulnerability of people living in the coastal zone has been demonstrated in numerous studies and is emphasised in the recent Third Assessment Report of the Intergovernmental Panel on Climate Change (IPCC, 2001). The subsiding coastal zone in Bangladesh is particularly vulnerable as it is affected by more than twice the mean predicted global rate of sea-level rise. The consequences are saltwater intrusion into surface and groundwater systems, drainage congestion and water logging, and changes in morphodynamic processes resulting in increased riverbank erosion. In addition, sea-level rise has the potential to make cyclones and coastal inundationeven more damaging than they are today.
\end{abstract}

The cyclones of 1991, 1994 and 1998 have created great awareness of the need and opportunities to prepare for cyclones and to reduce vulnerability. The prospect of climate change and sea-level rise increases the need to prepare for cyclones, whilst the development of an international climate adaptation regime increases the opportunities to do so. The Government of Bangladesh (GoB), together with development funding partners such as the World Bank, UNDP and others, has embarked on preparing its Poverty Reduction Strategy Paper (PRSP) as well as its National Adaptation Programme of Action (NAPA). Both the PRSP and the NAPA are likely to become key national planning documents, which will inform and guide investments in the coming years.

Civil society organisations have made major contributions to poverty alleviation and disaster reduction in Bangladesh. However, despite the wealth of information available and the initiatives being taken by both the GoB and civil society organisations, effective adaptation, aimed at protecting vulnerable households and livelihoods in exposed coastal communities, is constrained by the limited exchange of information between and within the GoB and civil society organisations. There is clearly a disconnect between, on the one hand, the widely declared need to start planning for adaptation at local, regional and national levels and, on the other hand, the knowledge base available at these levels to support such planning. 
1 Stockholm Environment Institute, Lilla Nygatan 1, Box 2142, 10314 Stockholm, Sweden.

2 Natural Resources Institute, University of Greenwich at Medway, Central Avenue, Chatham Maritime, Kent ME4 4TB, UK.

3 International Institute for Environment and Development, 3 Endsleigh Street, London WC1H ODD, UK.

4 Potsdam Institute for Climate Impact Research, P.O. Box 601203, 14412 Potsdam, Germany.

5 CARE Bangladesh, Pragati RPR Center, 20-21 Kawran Bazar, Dhaka-1215, Bangladesh.

Underlying this disconnect are a) a lack of information at the local level about the potential risks of climate change and about national and international approaches and policies to reduce these risks; and b) a lack of information at the national and international level about local vulnerabilities, adaptation needs and development opportunities. Focusing on Bangladesh's coastal zone, a project is being developed that aims to support and advance adaptation to climate change and its mainstreaming into development activities by:

- Enabling non-governmental organisations from the grassroots to the national level to work together in producing and sharing knowledge, insights and know-how;

- Producing and disseminating comprehensive and updated information on local and household level vulnerabilities to climate change;

- Developing a long-term vision towards establishing an effective and efficient dialogue between civil society organisations and the Government of Bangladesh on adaptation and development.

\section{Key words}

tropical cyclones, sea-level rise, community vulnerability, civil society, adaptation, mainstreaming, coastal planning, policy development, climate change, Bangladesh.

\section{Introduction}

Bangladesh (Figure 1) has a long history of severe impacts from climate-related hazards such as floods, droughts, tropical cyclones and storm surges. Despite the fact that the lives and livelihoods of the people living in the low-lying coastal areas and the islands (chars) in rivers and estuaries are frequently threatened by flooding and tropical cyclones, the fertile alluvial land is used intensively for agriculture which provides the main stake of the country's economy. With a population of more than 135 million in 2002, Bangladesh is one of the most populated countries in the world (World Bank, 2003). In the Ganges delta the population density exceeds 600 persons per $\mathrm{km}^{2}$ (Pachauri, 1992). Bangladesh is also one of the least developed countries and poverty is widespread with $34 \%$ of the people living below the national poverty line (World Bank 2003). Other indicators of low socio-economic development include a large rural population (74\%), a low life expectancy (62 years), a high illiteracy rate (59\%), and high infant mortality (52 per 1000 live births) (all numbers 1996-2002 averages, World Bank, 2003). Given the se socio-economic circumstances and the 
high frequency of occurrence of natural disasters many communities lack the resources to cope with current climate variability and extreme events in a preventive way.

Bangladesh experienced 30 cyclones from 1961 to 1998 (Banglapedia: National Encyclopedia of Bangladesh) and seven major floods from 1974 to 1998 (Matin, 1998). The most devastating natural disasters affecting Bangladesh in recent history are the cyclones of 1970, 1991, 1997 and 1998 and the floods of 1998. In November 1970 Bangladesh experienced the greatest tropical cyclone disaster last century when winds of up to $220 \mathrm{kmh}^{-1}$ coupled with a $10 \mathrm{~m}$ high storm surge killed up to 500,000 people (IFRC, 2002). Almost 140,000 people died and about 11 million people were affected as a result of a cyclone in April 1991. The cyclone with wind speeds of more than $220 \mathrm{kmh}^{-1}$ and a storm generated tidal surge in excess of $6 \mathrm{~m}$ devastated the coastal area southeast of Dhaka, destroyed 800,000 homes rendering millions of people homeless, and caused damage in excess of US\$ 1.5 billion (Haider et al., 1991; IFRC, 2002). More than 2.5 million people were evacuated during five cyclones in 1991 (IFRC, 2002). In May 1997, a cyclone with winds of over $230 \mathrm{kmh}^{-}$ ${ }^{1}$ and a tidal surge of up to $4.5 \mathrm{~m}$ claimed almost 200 lives and one million people were evacuated into cyclone shelters. In November 1998 cyclone 07B crossed the Sundarban-Barisal coast and about 100,000 people in southern Bangladesh were evacuated to cyclone shelters and concrete buildings. The associated tidal wave was up to $3 \mathrm{~m}$ high and temporarily flooded large areas of low-lying land (BBC, 1998). The flood of 1998 is considered to be one of the worst natural disasters experienced by the country in the 20th century. About 68 percent of the country's geographical area was flooded, affecting more than 30 million people and causing 918 fatalities (Choudhury 1998). Economic losses were estimated at US\$ 3.3 billion, equivalent to 8 percent of the country's GDP (Choudhury et al. 1999). Nicholls et al. (1995) estimate that 42 percent of the nearly 1.9 million cyclone-related deaths in the past two centuries have occurred in Bangladesh.

\section{The potential impacts of climate change on Bangladesh}

Whilst Bangladeshi communities are struggling to cope with current climatic conditions and the impacts of extreme climatic events on livelihoods and food security, the country is considered to be one of the most vulnerable countries to climate change. It is geographically exposed to a multitude of adverse impacts of climate change because of its location in the tropics in the delta of three of the world's biggest rivers and its flat low lying deltaic topography. At the same time, the country has low adaptive capacity because it is extremely poor. This vulnerability has been documented in many studies (e.g. ADB, 1994; Ali, 1996, 1999; IPCC TAR, 2001; Kauscher et al., 1996; Rijsberman and van Velzen, 1996; Warrick and Ahmad, 1996; World Bank, 2000). 


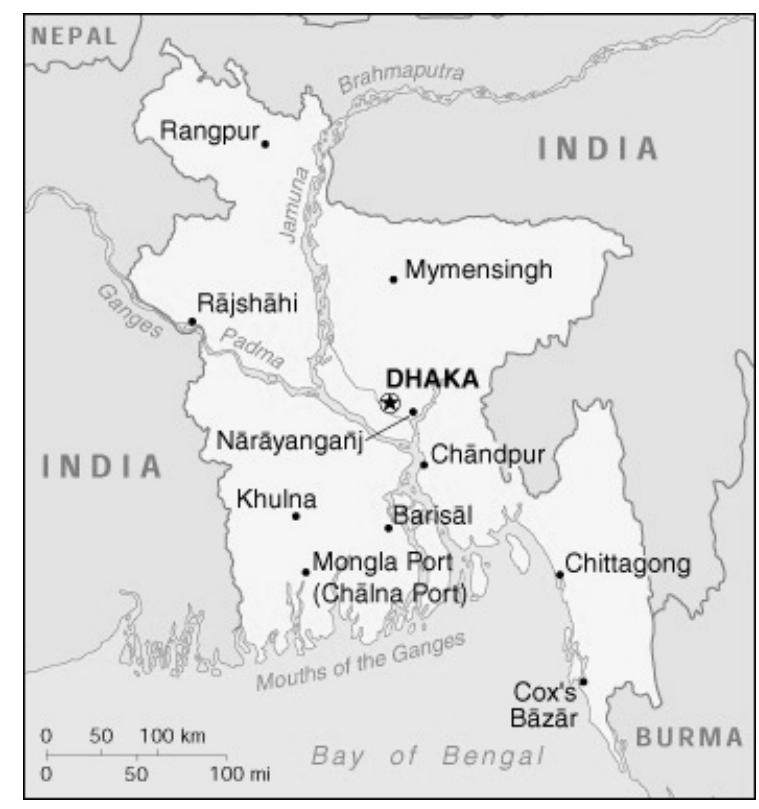

Figure 1: Map of Bangladesh (copyright CARE Bangladesh).

Large-scale subsidence of coastal areas combined with climate change induced sea level rise results in a relative rise in sea level which is more than twice the predicted global rate. Das and Radhakrishna (1991) documented a rise in mean sea level in the Bay of Bengal of $2.5 \mathrm{~mm}$ per year since the 1950s. An additional increase of 15 to 38 $\mathrm{cm}$ is expected by 2050 (Kumar et al., 2002). Without the protection of low-lying coastal areas elevated sea levels could lead to large-scale intrusion of salt water into surface and groundwater systems. This could have serious implications for drinking water supplies and food production. Sea level rise may also result in drainage congestion and water logging in the delta during high flow periods in the three major rivers. Finally, changes in the flow dynamics as a result of sea level rise could result in the erosion of river and estuary banks. The worst case scenario is the permanent displacement of people from the coast. Assuming a population of 1995 and no adaptation Nicholls et al. (1995) estimated that a one metre rise in sea level could displace as many as 15 million people. A more recent estimate by UNEP/GRIDArendal (2001) puts the number of displaced people at 17 million (15 percent of the population) for a rise in sea level of $1.5 \mathrm{~m}$ (Figure 2). Some studies have suggested the possibility of an increase in the intensity and frequency as well as changes in the paths of tropical cyclones in the Bay of Bengal as a result of increasing sea surface temperatures, but this is disputed by others (cf. Ali and Chowdhury, 1997; Emmanuel, 1988; ADB, 1994; Houghton et al., 1990; Bhaskar, 1997; Shuckla et al., 2002). Even though these processes are not well understood, cyclone-induced storm surges are likely to be more destructive in the future due to the elevated sea level. 


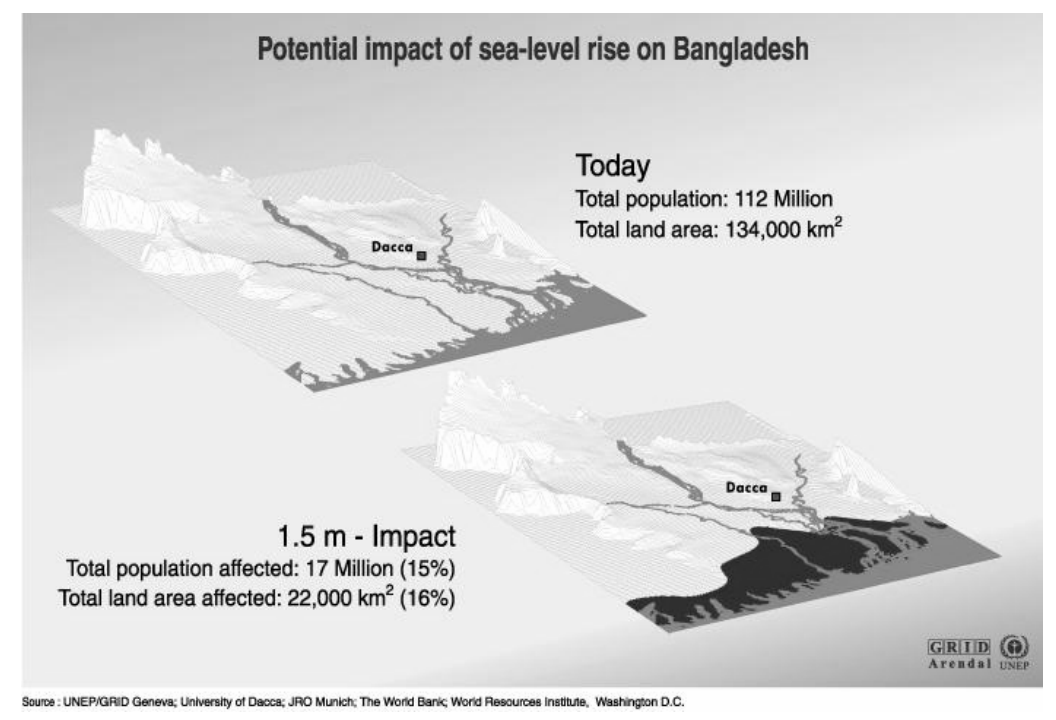

Figure 2: Potential impact of sea level rise on Bangladesh (Source: UNEP/GRIDArendal, 2001).

\section{The poor are particularly vulnerable to climate change}

According to the IPCC's Third Assessment Report (IPCC, 2001), developing countries are expected to suffer the most from the negative impacts of climate change. This is because climate-sensitive sectors such as agriculture and fisheries are economically particularly important and because these countries have limited human, institutional, and financial capacity to anticipate and respond to the direct and indirect effects of climate change. Many sectors providing basic livelihood services to the poor are not able to cope even with today's climate variability and stresses (Sperling, 2003). The frequent occurrence of extreme weather events such as the floods and tropical cyclones in Bangladesh can set back development in the country for decades. Many developing countries are already experiencing increasing stresses from climate variability and extremes and will do so increasingly in the future as climate change progresses (Sperling, 2003).

The adaptive capacity of affected poor communities and countries to climate change clearly needs to be increased but it is important to acknowledge that the impacts of climate change on people's lives and livelihoods will vary greatly depending on their existing vulnerabilities. For many people in developing countries climate change is not at the forefront of their concerns but rather one of many factors which keeps them in poverty. Vulnerability to climate change is determined by geographic location; economic, social, and cultural characteristics; prioritisation and concerns of individuals, households, and social groups; as well as institutional and political constraints (Sperling, 2003). So far much research has focused on investigating changes in the hydro-meteorological processes, identifying the locations particularly at risk, and on characterising and quantifying the impacts (e.g. changes in the 
frequency and intensity of tropical cyclones, max depth and extent of floodwater inundation, number of people at risk, etc.). Relatively few efforts have been made to understand the social and institutional factors which lead to the differential vulnerability of certain groups of people to negative climate change impacts. Thomalla and Schmuck (2004) examined the role of governmental organisations and NGOs in developing comprehensive disaster-preparedness programmes after the 1999 Orissa cyclone. They found that at community-level hazard awareness was high and that many of the lessons learnt in 1999 were put into practice during a cyclone in 2002. At the state level, however, government-NGO collaboration remains problematic. Howell (2001) and Schmuck (2002) found that in Bangladesh the landless migrants inhabiting the offshore chars are particularly vulnerable to floods and cyclones due to their highly exposed location, extreme poverty and social margialisation. There are also gender differences: often women are particularly vulnerable to natural hazards because of their traditional roles and responsibilities in the household and because of cultural factors (Cannon, 2002; Howell, 2001; Miller and Lindskog, in progress; Schmuck, 2003).

\section{The Role of civil society in reducing vulnerability to climate change}

Bangladesh is a democratic country with a healthy civil society in which many NGOs have made major positive contributions to poverty alleviationand the development of rural and urban communities, and are therefore an important sector for adaptation to climate change. Today about 10,000 non-governmental organisations (NGOs) operate in the country (Huq, 2004, pers. comm.). Bangladesh has some of the worlds largest NGOs (Rahman, 2002), such as BRAC (formerly known as Bangladesh Rural Advancement Committee) which has more than 45,000 employees and which has nationwide capacity and coverage. Many more local NGOs provide a multitude of services such as micro credit, social mobilisation, health, literacy and education, sanitation, water, agriculture, forestry, fisheries, disaster management, and advisory technical and consultancy services (Rahman, 2002). In recent years a number of networks of NGOs have been established in various sectors. Examples are the Coalition of Environmental NGOs (CEN) which has over 100 member NGOs working on environment-related issues and the Network for Information, Response and Preparedness Activities on Disaster (NIRAPAD). NIRAPAD was founded in 1997 and currently has 21 members. Its objective is to assist in creating sustainable organisational capabilities of member organisations in preparing themselves and their community to face disaster (www.nirapad.org).

Box 1 summarises the most important initiatives undertaken in Bangladesh to-date to protect people from the impacts of climate-related disasters such as cyclones and flooding. The timeline reflects the evolution of approaches from top-down structural protection measures such as the construction of concrete cyclone shelters and flood embankments in the 1960s, 1970s and 1980s to the initiation of more communitybased approaches by the Red Cross (Box 2) and other civil society organisations. 


\begin{tabular}{|c|c|}
\hline 1960s & Start construction of cyclone shelters \\
\hline 1970 s & $\begin{array}{l}\text { Initiation of the Cyclone Preparedness Programme (CPP) by the International Federation } \\
\text { of Red Cross/Red Crescent Societies (IFRC), the Bangladesh Red Crescent Society } \\
\text { (BDRCS) and the Government of Bangladesh (GoB) }\end{array}$ \\
\hline 1986-1994 & $\begin{array}{l}\text { Construction of } 30 \text { cyclone shelters by various Re d Cross societies and the German Bank } \\
\text { for Reconstruction (KfW) }\end{array}$ \\
\hline 1989 & Bangladesh Flood Action Plan (FAP) \\
\hline 1993 & Creation of the Disaster Management Bureau (DMB) \\
\hline 1996-2002 & $\begin{array}{l}\text { German Red Cross/Bangladesh Red Crescent Community Based Disaster Preparedness } \\
\text { Programme (CBDPP) }\end{array}$ \\
\hline 1997 & $\begin{array}{l}\text { Creation of the Network for Information, Response and Preparedness Activities on } \\
\text { Disaster (NIRAPAD) }\end{array}$ \\
\hline 2003-2005 & $\begin{array}{l}\text { Capacity strengthening of the Least Developed Countries (LDCs) for Adaptation to } \\
\text { Climate Change (CLACC) }\end{array}$ \\
\hline 2002-2005 & Reducing Vulnerability to Climate Change (RVCC) Project \\
\hline 2003 & $\begin{array}{l}\text { Creation of a Comprehensive Disaster Management Programme (CDMP) with funding } \\
\text { from UNDP and DFID }\end{array}$ \\
\hline 2003 & Interim Poverty Reduction Paper (PRSP) for Bangladesh \\
\hline 2004-2005 & $\begin{array}{l}\text { Formulation of the Bangladesh Programme of Action for Adaptation to Climate Change } \\
\text { (NAPA ) }\end{array}$ \\
\hline
\end{tabular}

Box 1: Timeline of important initiatives to reduce vulnerability to climate-related hazards.

Following the devastating 1988 floods, the Bangladesh Flood Action Plan (FAP), a large-scale international effort financed by the World Bank and fourteen donor nations which proposed the construction of several thousand kilometers of flood embankments along Bangladesh's three major rivers, was implemented in 1990. The plan was widely criticised for its high cost, the displacement of millions of people, the damage to inland fisheries through the disruption of fish migration paths, its failure to protect from extreme cyclone-induced tidal surges, and its lack of understanding or disregard of the beneficiary effects of monsoon floods for rural agriculture (Brammer, 1993; Farooque, 1993; Moberg and Olsson, 2003). The plan did also not specifically address the potential impacts of climate change on Bangladesh. Whilst the effectiveness of the FAP was yet again questioned in 1998 when tens of millions of people lost their homes during another major flood, some argue that the experiences from the FAP have resulted in the establishment of a holistic National Water Policy and a National Water Management Plan (Moberg and Olsson, 2003).

During the 1990s there was a major shift in the approach to hazard management and efforts got underway by many NGOs to move from providing post-disaster relief and humanitarian aid to a more preventive approach to hazard management by trying to increase the ability of local communities to prepare for and cope with natural hazards and to reduce the longer-term impacts on their livelihoods. Civil society organisations have also played an important role in strengthening the disaster management capabilities at the district and village levels. The Disaster Management Bureau (DMB) was established in 1993 under the Ministry of Disaster Management and 
Relief of the Government of Bangladesh with funding by UNDP, UNICEF and DFID. Working closely with NGOs, the DMB aims to reduce the loss of lives and property and to achieve self-reliance and sustainable development by collecting hazard-related data, developing disaster preparedness plans, conducting hazard awareness training programmes, and coordinat ing disaster management activities.

\begin{abstract}
The Bangladesh Red Crescent Community Based Disaster Preparedness Programme 1996-2002
After the 1991 cyclone a study by the Bangladesh Red Crescent Society and other organisations revealed that $90 \%$ of its victims were women and children and that despite the existence of some cyclone shelters, many people were not aware of their purpose or didn't feel it was safe to take refuge in them. In response to these findings the German Red Cross in 1996 initiated the Community Based Disaster Preparedness Programme (CBDPP) in Cox's Bazar District with the objective to improve the communities' self-help capacities. The programme was implemented by the Bangladesh Red Crescent together with communities living around 30 cyclone shelters along the most vulnerable points of the Bangladesh coastline. The shelters were constructed between 1986 and 1994 by various Red Cross societies and the German Bank for Reconstruction (KfW). To ensure active participation of all sectors of the community, gender specific micro groups with 15 to 25 members each were formed. Each of these groups elects one representative to be a member of the Village Disaster Preparedness Committee (VDPC), which is responsible for the use and maintenance of the cyclone shelters. The committee also conducts a range of disaster preparedness activities before, during and after the cyclone season. Each shelter also has a committee of 21 members, 11 male and 10 female. The CBDPP particularly aims to reduce the impact of cyclones on women and children and to empower them in their every day lives by paying special attention to them through group training sessions on disaster preparedness, leadership, reproductive health, nursery management techniques as well as small scale entrepreneurship such as chicken breeding. In 2002, the German Red Cross officially handed over responsibility for these activities to the Bangladesh Red Crescent Society and the local communities themselves.
\end{abstract}

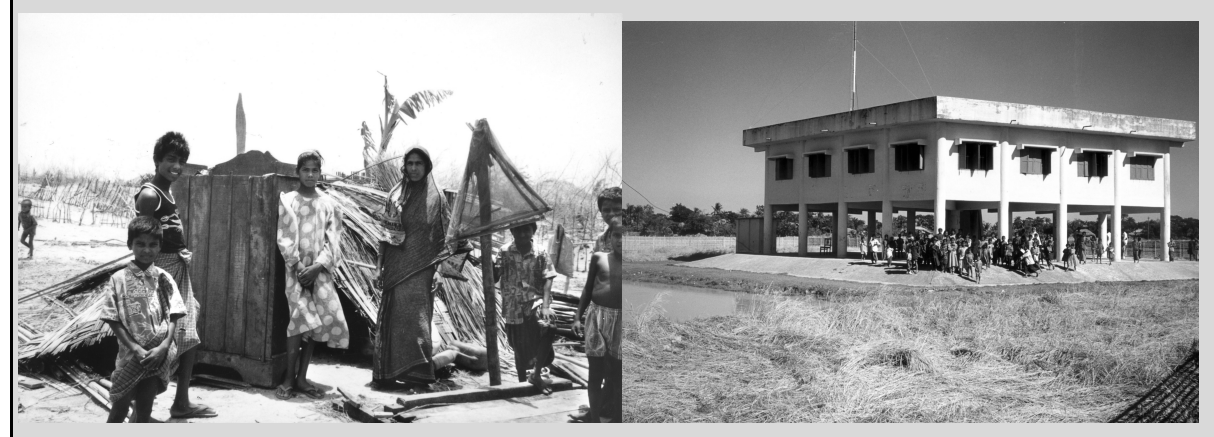

Figure 3: Left: Bangladeshi family in front of their destroyed bamboo house (photo by the Bangladesh Red Crescent Society, BDRCS). Right: Concrete cyclone shelter (photo by German Red Cross).

Box 2: The Bangladesh Red Crescent Community Based Disaster Preparedness Programme (Source: Schmuck, 2002; 2003).

The recent cyclones of 1991 and 1998 have created great awareness of the need and opportunities to prepare for cyclones and to reduce vulnerability in the long-term. The prospect of climate change and sea-level rise increases the need to prepare for cyclones, whilst the development of an international climate adaptation regime increases the opportunities to do so. The urgency to prepare for climate change has 
led to a number of large projects in Bangladesh during the last three years. The CLACC project (Capacity strengthening of the Least Developed Countries (LDCs) for Adaptation to Climate Change) was initiated in 2002 and aims to strengthen the capacity of civil society in LDCs to adapt to climate change, to enhance adaptive capacity among the most vulnerable groups, and to integrate adaptation to climate change into the work of key non-government institutions. The RVCC project (Reducing Vulnerability to Climate Change) is a 3-year project initiated in 2002 which works at four levels (household, community, institutional and national) to raise awareness to climate change, to adapt to environmental changes that could be exacerbated by climate change, and to influence relevant policy (see Box 3 for more details). A Comprehensive Disaster Management Programme (CDMP) was created in 2003 by the GoB and UNDP. Additional funding from DFID is specifically targeted to help Bangladesh cope with shocks resulting from climate change by supporting research, developing vulnerability reduction activities, and provid ing assistance to strengthen communities' abilities to cope with disasters (UNDP, 2003).

\section{Reducing Vulnerability to Climate Change (RVCC) Project 2002 to 2005}

The Reducing Vulnerability to Climate Change (RVCC) Project is the first initiative of its kind in Bangladesh. It is a 3-year project running from January 2002 to March 2005, funded by the Canadian International Development Agency (CIDA) and being implemented by CARE Bangladesh. The RVCC Project is working in six districts in southwestern Bangladesh through partnerships with local organizations and communities. The project goal is to increase the capacity of Bangladeshi communities in the southwest to adapt to the adverse effects of climate change. The Project has been designed to assist Bangladesh, a non-Annex 1 country, to adapt to the impacts of adverse climate change via the promotion of sustainable development and the building of local-level capacity to advocate on climate change issues. The project is working with communities and institutions to raise awareness on climate change, adapt to environmental changes that could be exacerbated by climate change, and influence relevant policy.

The project is working at four levels:

Household Level: The project is improving the capacity of 4,300 vulnerable households to adapt to climate change impacts by making them aware of new livelihood strategies, using a group-based approach. Staff belonging to 9 local partner organizations and 2 research organizations are training and supporting these households. Some of the alternative livelihood strategies being promoted include: hydroponics using water hyacinth as the base for the floating garden; crab fattening; reed cultivation and mat making; saline-tolerant non-rice crops; and, rainwater-harvesting systems.

Community Level: The project is training local partner organizations to work with 14 Union Parishads (lowest tier of elected government) and community leaders to increase their awareness of climate change impacts and to develop and implement community-level adaptation strategies, i.e., canal excavation to reduce waterlogging, raising of embankment to prevent intrusion of saline tidal water; pond-sand-filter for safe drinking water; and, construction of a new cyclone shelter.

Institutional Level: The project is supporting the capacity building of six local organizations in four areas:

- Collection and dissemination of information related to climate change, including publication of regular newsletters and a climate change information package written in easy-to-understand language, for use by partner organizations and journalists. 


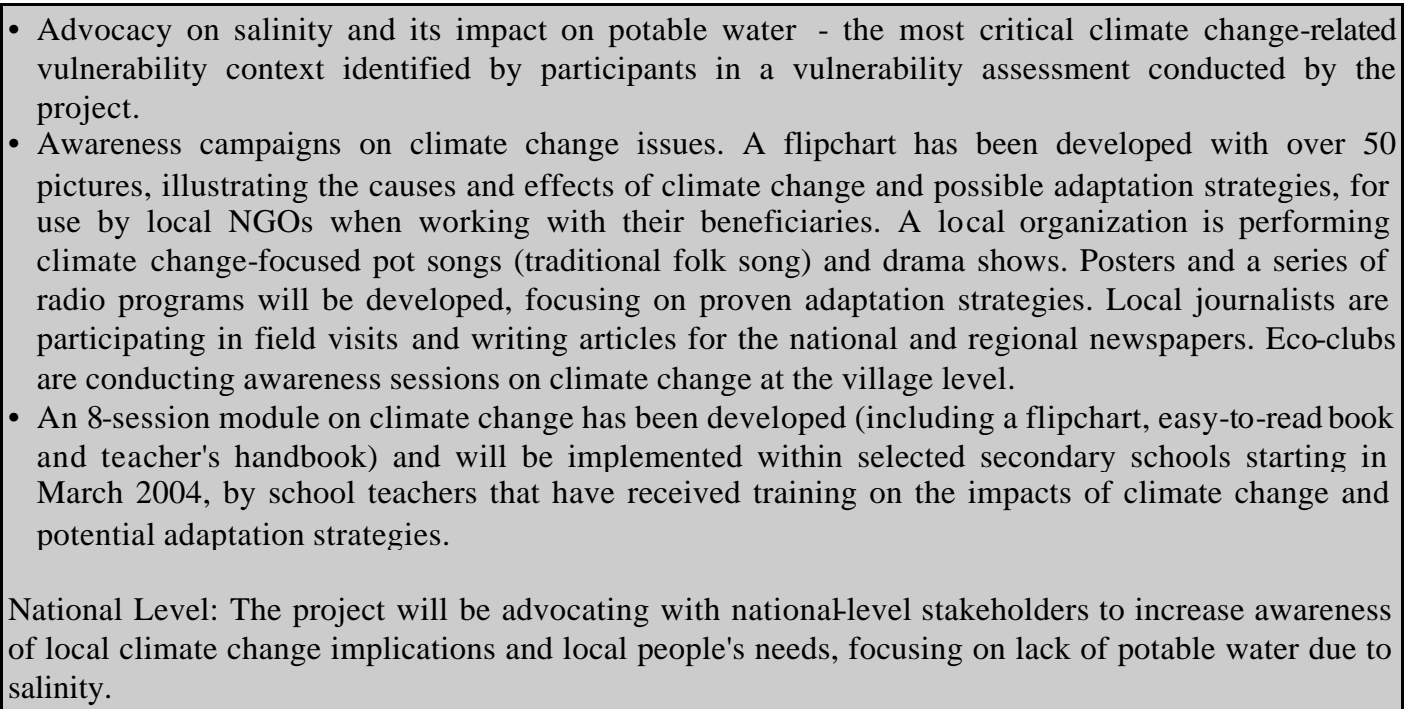

Box 3: Reducing Vulnerability to Climate Change (RVCC) (CARE, 2004; RVCC, 2002; 2004).

\section{Recent planning developments at the national and international levels}

In 2003 the GoB, together with development funding partners such as the World Bank, UNDP and others, embarked on preparing the country's Poverty Reduction Strategy Paper (PRSP) (IMF, 2003). PRSPs describe a country's macroeconomic, structural and social policies and programmes to promote growth and reduce poverty, and identify external financing needs. Because climate change impacts add additional stress to the existing vulnerabilities of the poor in terms of their livelihood security, health and economic opportunities, climate change may seriously threaten the realisation of the Millennium Developments Goals (MDGs). Policies aimed at reducing the impacts of climate change therefore clearly need to be integrated with development and poverty reduction strategies (Huq and Khan, 2003; Klein et al, 2004; Smit et al, 2001). This year Bangladesh has also started with the preparations for the development of its National Adaptation Plan of Action (NAPA). NAPAs are undertaken for each of the World's Least Developed Countries (LDC) under the United Nations Framework Convention on Climate Change (UNFCCC). Funding for this process is provided by the UNFCCC's Least Developed Countries Fund. The $\mathrm{GoB}$ is currently implementing the project "Formulation of the Bangladesh Programme of Action for Adaptation to Climate Change (NAPA) with financial support from Global Environment Facility (GEF) through United Nations Development Programme (UNDP). The Bangladesh Centre for Advanced Studies (BCAS), one of Bangladesh's leading non-governmental policy, research and implementation institutes, is a member of the steering committee and is provid ing significant technical input to this report with regard to water, coastal area, natural disasters and health, and industry and infrastructure. Both the PRSP and the NAPA 
are likely to become key national planning documents, which will inform and guide investments in the coming years. It is important that the voices and concerns of the poor, particularly the most vulnerable groups in the country, are fed into the PRSP and NAPA processes.

\section{Need for greater information exchange between the GoB and NGOs}

Even though the NGO sector is in principle controlled by the GoB, and NGOs and the GoB have similar development objectives, collaboration between them is not well developed, although there is a growing recognition that the public, private and NGO sectors should make a concerted effort to improve collaboration. There exists a disconnect between, on the one hand, the widely declared need to start planning for adaptation at local, regional and national levels and, on the other hand, the knowledge base available at these levels to support such planning. This disconnect is based on two issues: The first is a lack of information at the local level about the potential risks of climate change and about national and international approaches and policies to reduce these risks. The second is a lack of information at the national and international level about local vulnerabilities, adaptation needs and development opportunities. These two types of information deficit are not due to the non-existence of the relevant information. There is a wealth of information available, but for a variety of reasons relevant actors are either unaware of it, do not have access to it or cannot use it in the form in which it is made available. There is a mismatch between the information that is available, both at the local level and at the national and international level, and the information that is required at each level to engage successfully in adaptation to climate change and its mainstreaming in development activities. To address these information deficits, it will be necessary to produce relevant information, raise awareness and build capacity, and develop mechanisms to ensure an effective exchange of information from grassroots levels to national and international policymaking and vice versa.

\section{Building civil society alliances to support adaptation mainstreaming}

An international consortium consisting of the Stockholm Environment Institute, the Natural Resources Institute at the University of Greenwich, the International Institute for Environment and Development, the Potsdam Institute for Climate Impact Research, The World Conservation Union (IUCN), CARE Bangladesh and the Bangladesh Centre for Advanced Studies is currently developing a project which aims to support and advance adaptation to climate change and its mainstreaming into development activities in Bangladesh It is envisaged that these goals will be achieved by enabling NGOs from the grassroots to the national level to work together in producing and sharing knowledge, insights and know-how; producing and disseminating comprehensive and updated information on climate change; and developing a long-term NGO vision towards establishing an effective and efficient dialogue with the GoB on adaptation and development. 
The two main components of the proposed study are awareness raising and capacity building and the development of mechanisms which will ensure a more effective exchange of information. Awareness raising and capacity building activities will target NGOs, vulnerable coastal communities and schools and will include the conducting of training and dissemination workshops; the publication of scientific and technical information in a form that is clear, straightforward and connects to people's daily lives; and the setting up of school programmes. These activities will enhance the knowledge base of key actors in the process of local adaptation and mainstreaming into development activities.

The second component will create the conditions for non-governmental organisations to build an alliance that can complement and contribute to the governmental and intergovernmental processes currently shaping adaptation and mainstreaming in Bangladesh. This will involve the creation of a shared strategy towards adaptation and mainstreaming; the establishment of one or several offices from where alliance activities will be co-ordinated and results will be disseminated; and the development of online tools for communication, training and networking.

\section{Local and national needs inventory}

One of the most fundamental aspects of adaptation to climate change is the capacity of the people who rely mainly on farming for their livelihoods to alter their activities. This might include choosing different crop varieties and cropping patterns and making use of livestock opportunities. These choices are constrained by a number of other factors such as the availability of fodder, crop residues and appropriate construction materials. An inventory of existing knowledge and practice of the potential for livelihood adaptation will be conducted in conjunction with local NGOs and other relevant institutions. The objective is to gain a better understanding of local knowledge and resources available for the adaptation of livelihoods, since this forms the core of people's income and nutritional needs. This will be compared with evaluations dom in conjunction with local NGOs and institutions at local and national level of the food security needs of different regions of the country under different climate scenarios. In this way, an assessment of the mismatch between information at the different levels can be made, and a method by which NGOs can assist in bridging that gap and highlighting the components of rural livelihoods that need increased support can be developed. A further key aspect of climate change adaptation will be the resilience of structures such as homes, schools and other public buildings to the increased hazard risk. The project will provide the basis for matching local knowledge and needs assessment with nationallevel information and budget expectations. This will enable localities to identify the degree that local livelihoods (which are likely to be increasingly badly affected by coastal hazards) will or will not be able to permit the poor to improve their home structures to be wind and flood resistant, and the extent that local authorities will be able to protect schools and other public buildings. 
The work will be conducted by means of a sample participatory assessment in a number of zilla in three relevant coastal districts, in conjunction with the relevant local NGOs. Local livelihoods will be assessed and the extent to which local farmers, fishermen and other groups have the capacity for adaptive processes will be evaluated. This will include an assessment of existing degrees of flexibility in livelihood activities (e.g. varieties of staples planted, cropping patterns) and other measures of adaptation. In addition to the direct assessment of livelihood adaptability, a further survey will evaluate the degree to which existing knowledge and practices can enable the rural poor to adapt to hazard threats under conditions of climate change. This will be done especially in areas of drinking water supply, sanitation arrangements, home structures and resilience to wind and flood, and the potential for adaptation of public buildings and significant employers to wind and flood damage. This action is dependent on a participatory approach in order to obtain direct and relevant data from local people in a representative sample of communities. The assumption is that relevant knowledge is available, but that it has not been adequately collected in relation to hazards and climate adaptation. Relevant local NGOs can provide a trusted and relatively focused and experienced access to that information, and are well positioned to maintain and replicate that approach in other areas.

\section{Conclusions}

As late as the early 1990s, climate change was still generally considered a future challenge that could be managed by taking timely action towards reducing greenhouse gas emissions (i.e., mitigation). However, it has since become clear that no mitigation effort, however rigorous, is going to prevent climate change from happening in the next few decades. It is therefore increasingly evident that, in addition to policies aimed at mitigation, it is also now necessary to encourage the development of policies focused on adaptation to the effects of climate change. Reflecting a growing international recognition of the need to support adaptation strategies, the signatories to the UNFCCC agreed in 2001 to set up three funds to support adaptation initiatives in developing countries. One of these so-called "Marrakech Funds" is aimed specifically at supporting National Adaptation Programmes of Action (NAPAs) in the least developed countries (LDCs). These NAPAs provide a vehicle by which LDCs can communicate priority activities that address their immediate needs and concerns relating to adaptation to climate change.

In view of the apparent mismatch in Bangladesh between the information available and the information required at different scales, there is a concern that the NAPAs may not be able to fully consider local knowledge and local priorities regarding climate variability and change due to limited time and resources. In addition, given the climate policy context within which the NAPAs are being prepared, opportunities for mainstreaming adaptation to climate change into development activities may be limited. This consortium has been created to address this mismatch and to ensure that opportunities are not missed by providing a structure within which NGOs working on different spatial scales can exchange information, and where international 
organisations such as the Red Cross and IUCN can feed local knowledge, insights and know-how produced by grassroots NGOs into the national and international policy debates on adaptation to climate change. In addition, the efforts proposed in this paper will focus strongly on awareness raising and capacity building of NGOs and the GoB, thus enabling and empowering them to develop and implement effective adaptation approaches.

It is expected that the NAPA for Bangladesh will identify adaptation priorities which will get further funding from the LDC Fund and other UNFCCC Funds such as the Special Climate Change Fund. Investments in adaptation to climate change in the country are likely to occur for many years to come. The proposed project will ensure that such investments are better informed from the perspective of the most vulnerable groups and communities. In specific structural terms it is expected that the consortium will become a member of the inter-governmental committee on Adaptation to Climate Change (or a similar structure that is likely to be created for the NAPA implementation). This will ensure long-term inputs of the voices of the most vulnerable groups in national planning on adaptation to climate change. With respect to the larger development planning programme through the PRSP process, this consortium will seek to have a similar inputs into the national planning process.

\section{Acknowledgements}

Atiq Rahman and Mozaharul Alam of the Bangladesh Centre for Advanced Studies, Verena Kresin of the German Red Cross, and Hanna Schmuck contributed substantial text input and advice. Financial support for writing this paper was provided by the Stockholm Environment Institute through the institute's Poverty and Vulnerability Programme, which is funded by the Swedish International Development Cooperation Agency (Sida).

\section{References}

ADB. (1994). Climate change in Asia: Bangladesh Country Report. Regional study on global environmental issues. Asian Development Bank. Regional Study on Global Environmental Issues series, Manila, The Philippines.

Ali, A. (1996). "Vulnerability of Bangladesh to climate change and sea level rise through tropical cyclones and storm surges." Journal of Water Air Soil Pollution 92, d, 171179.

Ali, A. (1999). "Climate change impacts and adaptation assessment in Bangladesh." Climate Research 12, 109-116.

Ali, A. and J. U. Chowdhury. (1997). "Tropical cyclone risk assessment with special reference to Bangladesh." Mausam 48, 305-322.

Bhaskar, R. (1997). "Tropical cyclone simulation with Emanuel's convection scheme." Mausam 48, 113-122.

BBC. (1998). World: South Asia cyclone batters Bangladesh. BBC News Online, 23 November 1998 (available at: http://news.bbc.co.uk/1/hi/world/south_asia /219933.stm). 
Brammer, H. (1993). "Protecting Bangladesh.” Tiempo 8, April 1993.

Cannon, T. (2002). "Gender and climate hazards in Bangladesh." Gender and Development $10(2), 45-50$.

CARE. (2004). "Reducing vulnerability to c limate change (RVCC) project." Care Bangladesh, Dhaka, Bangladesh. http://www.carebd.org/project_dtls.php?pid=11.

Choudhury, O. H., K. M. Nabiul Islam, and D. Bhattacharya. (1999). "The losses of 1998 flood and its impact on the national economy." Bangladesh Institute of for Development Studies (BIDS), Dhaka, Bangladesh.

Choudhury, S. H. M. (1998). "Report on Bangladesh flood 1998: chronology, damages and responses." Management Information and Monitoring (MIM) Division, Disaster Management Bureau, Government of Bangladesh, Dhaka, Bangladesh.

Chowdhury, A. M. R., A. U. Bhuyia, A. Y. Choudhury, and R. Sen. (1993). "The Bangladesh cyclone of 1991: why so many people died." Disasters 17 (4), 291-304.

Das, P.K. and M. Radhakrishna. (1991). "Trends and pole tide in Indian tide gauge records." Proceedings of the Indian Academy of Sciences (Earth and Planetary Sciences) 100, $177-94$.

Emmanuel, K.A. (1988). "The dependence of hurricane intensity on climate." Nature 326, 483-485.

Farooque, M. (1993). “A legal perspective on the FAP.” Tiempo 8, April 1993.

Haider, R., A.A. Rahman, and S. Huq (eds.). (1991). "Cyclone '91. An environmental and perceptional study." Bangladesh Centre for Advanced Studies (BCAS), Dhaka, Bangladesh, $91 \mathrm{pp}$.

Haque, C. E. (1997). "Atmospheric hazards preparedness in Bangladesh: a study of warning, adjustments and recovery from the April 1991 cyclone." Natural Hazards 16, 181202.

Haque, C. E. and D. Blair. (1992). "Vulnerability to tropical cyclones: evidence from the April 1991 cyclone to coastal Bangladesh." Disasters 16, 3, 217-229.

Houghton, J.T., G.T. Jenkins and J.J. Ephramus (eds.). (1990). Climate Change: The IPCC Scientific Assessment. Cambridge University Press, Cambridge.

Howell, P. (2001). "Disaster preparedness on the coastal chars of Bangladesh." Humanitarian Practice Network, 6 April 2001.

Huq, S., A. U. Ahmed and R. Koudstaal. (1996). "Vulnerability of Bangladesh to climate change and sea level rise." In: T. E. Downing (Ed.), Climate Change and World Food Security. NATO ASI Series, Vol.: 137, Springer-Verlag, Berlin, 1996.

Huq, S. and M. Khan. (2003). "Mainstreaming national adaptation plans." Tiempo 49, September 2003.

Huq, S., Z. Karim, M. Asaduzzaman, and F. Mahtab, eds. (1999). Vulnerability and adaptation to climate change for Bangladesh. Dordrecht, The Netherlands: Kluwer Academic Publishers.

IFRC (2002) World Disasters Report. International Federation of Red Cross and Red Crescent Societies, Geneva, Switzerland, 239 pp.

IMF. (2003). Bangladesh: Interim Poverty Reduction Strategy Paper. International Monetary Fund, IMF Country Report No. 03/177, June 2003, 146 pp.

IPCC (2001) Science of Climate Change - Third Assessment Report (TAR) of the Intergovernmental Panel on Climate Change. Cambridge University Press, Cambridge.

Islam, M. R. (2004). "Where land meets the sea - a profile of the coastal zone of Bangladesh.” The University Press Ltd., Dhaka, July 2004. 
Kausher, A., R. C. Kay, M. Asaduzzaman, and S. Paul. (1994). "Climate change and sea level rise: the case of the Bangladesh coast." Dhaka, Bangladesh: Bangladesh Unnayan Parishad, Dhaka; Centre for Environment and Resource Studies, New Zealand; and Climatic Research Unit, England.

Klein, R.J.T., E.L. Schipper and S. Dessai. (2004). "Integrating mitigation and adaptation into climate and development policy: three research questions." Environmental Science and Policy, submitted.

Kumar, K.R., K.K. Kumar, R.G. Ashrit, S.K. Patwardhan and G.B. Pant. (2002). "Climate change in India: observations and model projections." In: P.R. Shukla, S.K. Sharma and P.V. Ramana (eds.) Climate change and India: issues, concerns and opportunities. Tata McGraw-Hill, New Delhi.

Matin, M.A. (1998). "Some lessons to be learnt from the 1998 flood." The Daily Star, Dhaka, Bangladesh, 1 September 1998.

Miller, F. and E. Lindskog. (in progress). "Gender, institutions and floods in Vietnam." Project of the Stockholm Environment Institute, Sweden.

Moberg, F. and P. Olsson. (2003). "Dancing with the river or drowning in aid in Bangladesh." (editorial). Sustainable Development Update 1 (3), February 2003.

Nicholls, R. J. N., N. Mimura and J. C. Topping. (1995). "Climate change in South and Southeast Asia: some implications for coastal areas." Journal of Global Environmental Engineering 1, 137-154.

Pachauri, R. K. (1992). "Global warming: impacts and implications for South Asia." In: Schmandt, J. and J. Clarkson (eds.), The Regions and Global Warming: Impacts and Response Strategies, Oxford University Press, New York, 79 pp.

Rahman, A. (2002). Policy livelihood relationship in South Asia. Role of NGOs in advocacy: lessons learnt from Bangladesh and South Asian countries. Bangladesh Centre for Advanced Studies (BCAS), Dhaka, Bangladesh, January 2002, 27 pp.

Rijsberman, F. R. and A. V. Velzen. (1996). "Vulnerability and adaptation assessments of climate change and sea-level rise in the coastal zone: perspectives from the Netherlands and Bangladesh.” In: J. B. Smith (ed.), Adapting to climate change: An international perspective, Springer Verlag, New York, 322-334.

RVCC. (2002). Community vulnerability assessment in southwest Bangladesh. Reducing Vulnerability to Climate Change (RVCC) Project, CARE Bangladesh, September 2002.

RVCC. (2004). Annual report for the period of 1 July 2003 to 30 June 2004. Reducing Vulnerability to Climate Change (RVCC) Project, CARE Bangladesh, 2004.

Schmuck, H. (2002). "Empowering women in Bangladesh." Asia Pacific FOCUS, International Federation of Red Cross and Red Crescent Societies (IFRC), Februar 2002.

Schmuck, H. (2003). "Leben mit Zyklonen. Partizipative Strategien zur Vorbereitung auf Naturrisiken in Cox's Bazar, Bangladesh." Geographische Rundschau, 11/2003, S. 34-39.

Shukla, P.R., S.K. Sharma and P.V. Ramana (eds.). (2002). Climate change and India: issues, concerns and opportunities. Tata McGraw-Hill, New Delhi.

Smit, B., O. Pilifosova, I. Burton, B. Challenger, S. Huq, R.J.T. Kle in and G. Yohe. (2001). "Adaptation to climate change in the context of sustainable development and equity." In: Climate Change 2001: Impacts, Adaptation and Vulnerability, J.J. McCarthy, O.F. Canziano and N. Leary (eds.), Contribution of Working Group II to the Third Assessment Report of the Intergovernmental Panel on Climate Change, Cambridge University Press, Cambridge, UK, 877-912. 
SMRC. (2000a). "The vulnerability assessment of the SAARC coastal region due to sea level rise: Bangladesh case." SMRC Publication No. 3. SAARC Meteorological Research Centre, Dhaka, July 2000.

SMRC. (2000b). "Recent climatic changes in Bangladesh." SMRC Publication No. 4. SAARC Meteorological Research Centre, Dhaka, September 2000.

Sperling, F. (ed.). (2003). "Poverty and climate change: reducing the vulnerability of the poor through adaptation." African Development Bank; Asian Development Bank; Department for International Development, United Kingdom; Directorate-General for Development, European Commission; Federal Ministry for Economic Cooperation and Development, Germany; Ministry of Foreign Affairs, The Netherlands; Organization for Economic Cooperation and Development; United Nations Development Programme; United Nations Environment Programme and The World Bank. Published by MediaCompany, Berlin, Germany, 43 pp.

Thomalla, F. and H. Schmuck. (2004). "We all knew that a cyclone was coming: disaster preparedness and the cyclone of 1999 in Orissa, India." Disasters 28(4), 255-269.

UNDP. (2003). "UK boosts Bangladesh efforts to protect millions from disasters." News Feature 8 May 2003. United Nations Development Programme. Available at http://www.un-bd.org/undp/feature/2003/0203/0503/.

UNEP/GRID-Arendal. (2001). "Potential impact of sea level rise on Bangladesh." Vital Climate Graphics: Potential Impacts of climate change, http://www.grida.no/climate/vital/33.htm (2 November 2004).

Warrick, R.A. and Q.K. Ahmad, eds. (1996). The implications of climate and sea level change for Bangladesh. Kluwer Academic Publishers, Dordrecht, The Netherlands.

Wisner, B., P. Blaikie, T. Cannon and I. Davis (eds.). (2003). At risk: natural hazards, people's vulnerability and disasters. 2nd edition, Routledge 2003.

World Bank. (2003). Poverty in Bangladesh: building on progress. Poverty Reduction and Economic Management Sector Unit, South Asia Region, Report No. 24299-BD, December, 2002.

World Bank. (2000). Bangladesh: climate change and sustainable development. South Asia Rural Development Team, Report No. 21104 BD, Dhaka, Bangladesh. 